\title{
PERSISTENT SCATTERER INTERFEROMETRY USING SENTINEL-1 DATA
}

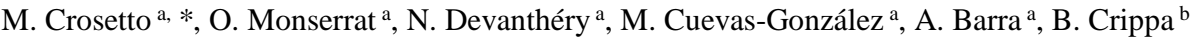 \\ a Centre Tecnològic de Telecomunicacions de Catalunya (CTTC), Division of Geomatics \\ Av. Gauss 7, E-08860, Castelldefels (Barcelona), Spain - (mcrosetto, omonserrat, ndevanthery, mcuevas, abarra)@cttc.cat \\ b Department of Geophysics, University of Milan, Via Cicognara 7, I-20129, Milan, Italy - bruno.crippa@unimi.it
}

\section{Commission VII, WG VII/2}

KEY WORDS: Radar, SAR, Interferometry, C-band, Deformation, Monitoring.

\begin{abstract}
:
This paper is focused on deformation monitoring using a Persistent Scatterer Interferometry technique and the interferometric SAR data acquired by the Sentinel-1 satellite of the European Space Agency. The first part of the paper describes the procedure used to process and analyze Sentinel-1 interferometric SAR data. Two main approaches are described. The first one is a simplified Persistent Scatterer Interferometry approach that exploits two key properties of the Sentinel-1 data: the high coherence of the 12-day interferograms and the reduced orbital tube. The second approach is a full Persistent Scatterer Interferometry approach, where a more sophisticate data treatment is employed. The second part of the paper illustrates the results obtained with the two processing approaches. Two case studies are described. The first one concerns landslide detection and monitoring. In this case, the simplified Persistent Scatterer Interferometry approach was used. The second one regards the deformation monitoring of an urban area. In this case, a full Persistent Scatterer Interferometry approach was used.
\end{abstract}

\section{INTRODUCTION}

Differential Interferometric SAR (DInSAR) is a powerful tool to detect and monitor ground deformation. An advanced class of the DInSAR techniques is given by Persistent Scatterer Interferometry (PSI), see Crosetto et al. (2016). This paper is focused on DInSAR and PSI for deformation monitoring using the SAR data acquired by the Sentinel-1 satellite of the European Space Agency. In the literature are described many examples of successful deformation monitoring results using different radar sensors, which demonstrated the DInSAR and PSI potential for a wide range of applications (Crosetto et al., 2016). Some examples are listed below:

- $\quad$ Landslides (Colesanti et al., 2003; Hilley et al., 2004; Bovenga et al., 2012).

- Land subsidence (Tomás et al., 2005; Stramondo et al., 2007; Bell et al., 2008; Heleno et al., 2011).

- $\quad$ Mining (Colesanti et al., 2005; Jung et al., 2007).

- Urban applications (Crosetto et al., 2008; Vallone et al., 2008; Cigna et al., 2012).

The DInSAR and PSI techniques have experienced a major development in the last two decades, which is mainly related to the progress accomplished through the exploitation of C-band data from the ERS-1/2, Envisat and Radarsat missions. The data acquired by these satellites covers long periods of time, a key aspect to guarantee a long-term deformation monitoring. The advent, in 2007, of very high resolution X-band data enabled a major step forward in the PSI techniques, including the capability to generate a dense sampling of Persistent Scatterers (PSs), a higher sensitivity to small displacements and a remarkable quality improvement of the time series compared to the C-band (Crosetto et al., 2010), e.g. see Figure 1.
A new significant improvement is expected to occur thanks to the data acquired by the sensor onboard the Sentinel- 1 satellite. This satellite, launched on 3 April 2014, acquires radar images in C-band and offers an improved data acquisition capability with respect to previous C-band sensors (ERS-1/2, Envisat and Radarsat), increasing considerably the deformation monitoring potential. Sentinel-1, in its standard data acquisition mode (Interferometric Wide Swath - IWS), acquires images covering 250 by $180 \mathrm{~km}$ with a revisiting cycle of 12 days. This cycle will become 6 days with the launch of the Sentinel-1B satellite. The Sentinel-1 coverage will be essential to develop wide-area PSI monitoring applications. An additional advantage of Sentinel-1 data is that they are available free of charge to all data users: general public, scientific and commercial users.

This article presents the authors' first experience with Sentinel-1 data. In the first part of the paper, the data processing and analysis strategies are briefly discussed. In the second one, two deformation measurement results are described.

\section{DATA PROCESSING AND ANALYSIS}

The Sentinel-1 IWS data require extra processing with respect to the standard processing used with StripMap data. This is due to the characteristics of the TOPS (Terrain Observation by Progressive Scan) imaging mode (Yague et al., 2016): the TOPS acquisition geometry (variable squint angle) requires a more complex elaboration of SAR images. This processing mainly concerns the image co-registration step, which needs to be very accurate (Prats-Iraola et al., 2012).

After the precise image co-registration, in order to process and analyse Sentinel-1 interferometric data, we basically use two complementary approaches: a simplified PSI method and a full PSI approach. The two approaches are discussed below. 


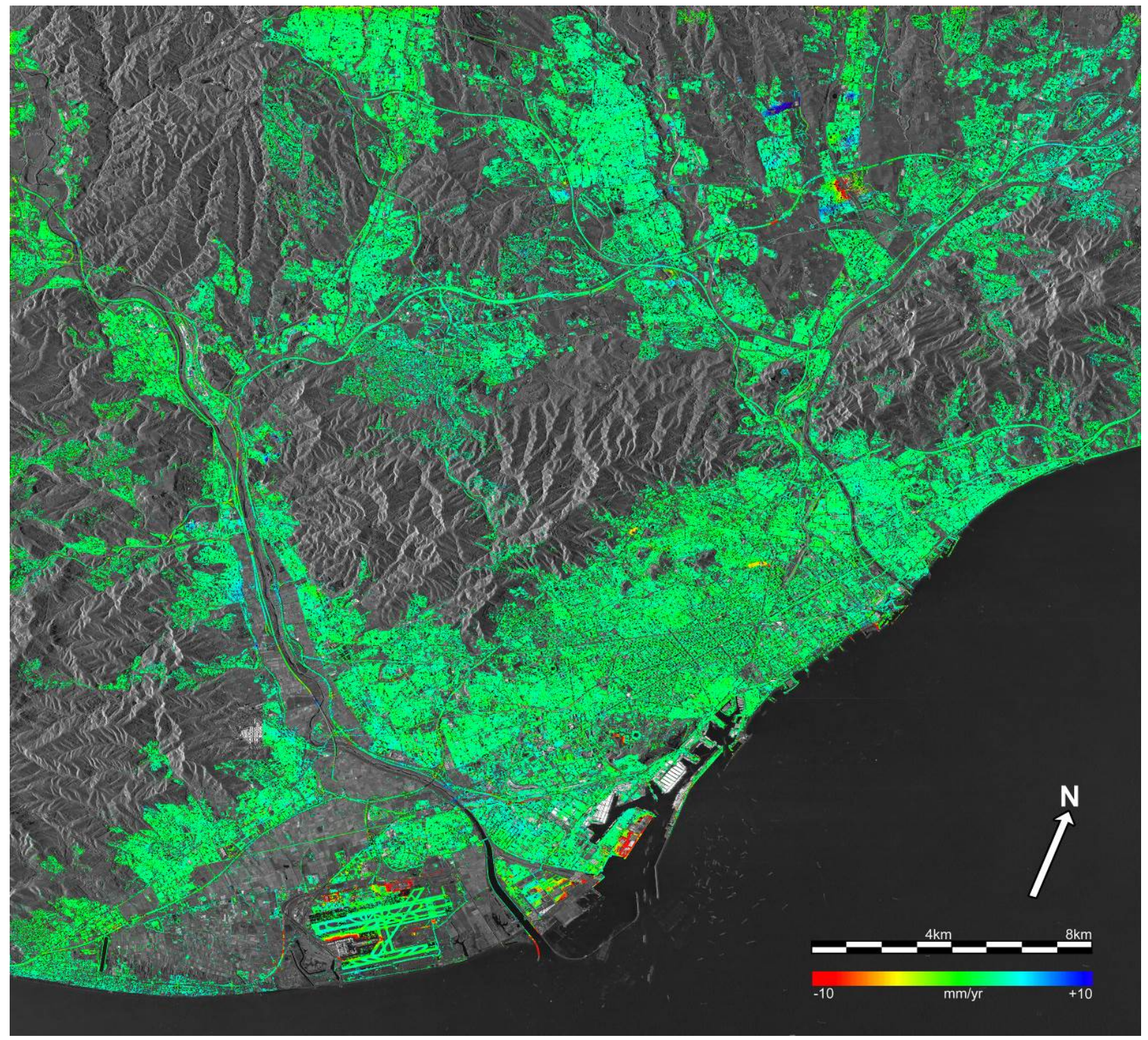

Figure 1: Deformation velocity map of the Barcelona dataset superposed to a mean SAR amplitude image. The map includes more than 5.4 million PSs and covers $1019 \mathrm{~km}^{2}$. It was derived using 28 very high-resolution TerraSAR-X images that span the period from December 2007 to November 2009.

\subsection{A simplified PSI approach}

This approach exploits two key aspects of the Sentinel-1 data. The first one is the increased interferometric coherence, which is mainly due to the short revisiting cycle of these data. The approach exploits temporally consecutive interferograms. The best results are achieved using series of 12-day interferograms, to fully exploit their high coherence. The second aspect is the reduced orbital tube of Sentinel-1, which decreases the importance of the so-called residual topographic phase component. In this approach, this phase component is neglected. These are the main steps of the procedure:

- $\quad$ Given a stack of N complex SAR images, generate the $\mathrm{N}-1$ consecutive multi-look interferograms. Typical multi-looks are 5 by 1,10 by 2 and 20 by 4 (range and azimuth).

- Perform a 2D phase unwrapping of the N-1 interferograms. This is done separately on each interferogram using the Minimum Cost Flow method (Costantini, 1998).

- Directly integrate the interferometric phases, to obtain temporally ordered phases in correspondence of the image acquisition dates. The phase of the first image is usually set to zero.

- Estimation of the atmospheric phase screen (APS) component and its removal. This is performed by means of a set of spatio-temporal filters (Ferretti et al., 2000; 2001).

- $\quad$ The deformation time series are derived by removing the atmospheric phase component.

- Data geocoding.

\subsection{A full PSI approach}

The full PSI approach requires a redundant net of $M$ interferograms, with $\mathrm{M}>>\mathrm{N}$, where $\mathrm{N}$ is the number of SAR complex images. The main processing steps, which are 

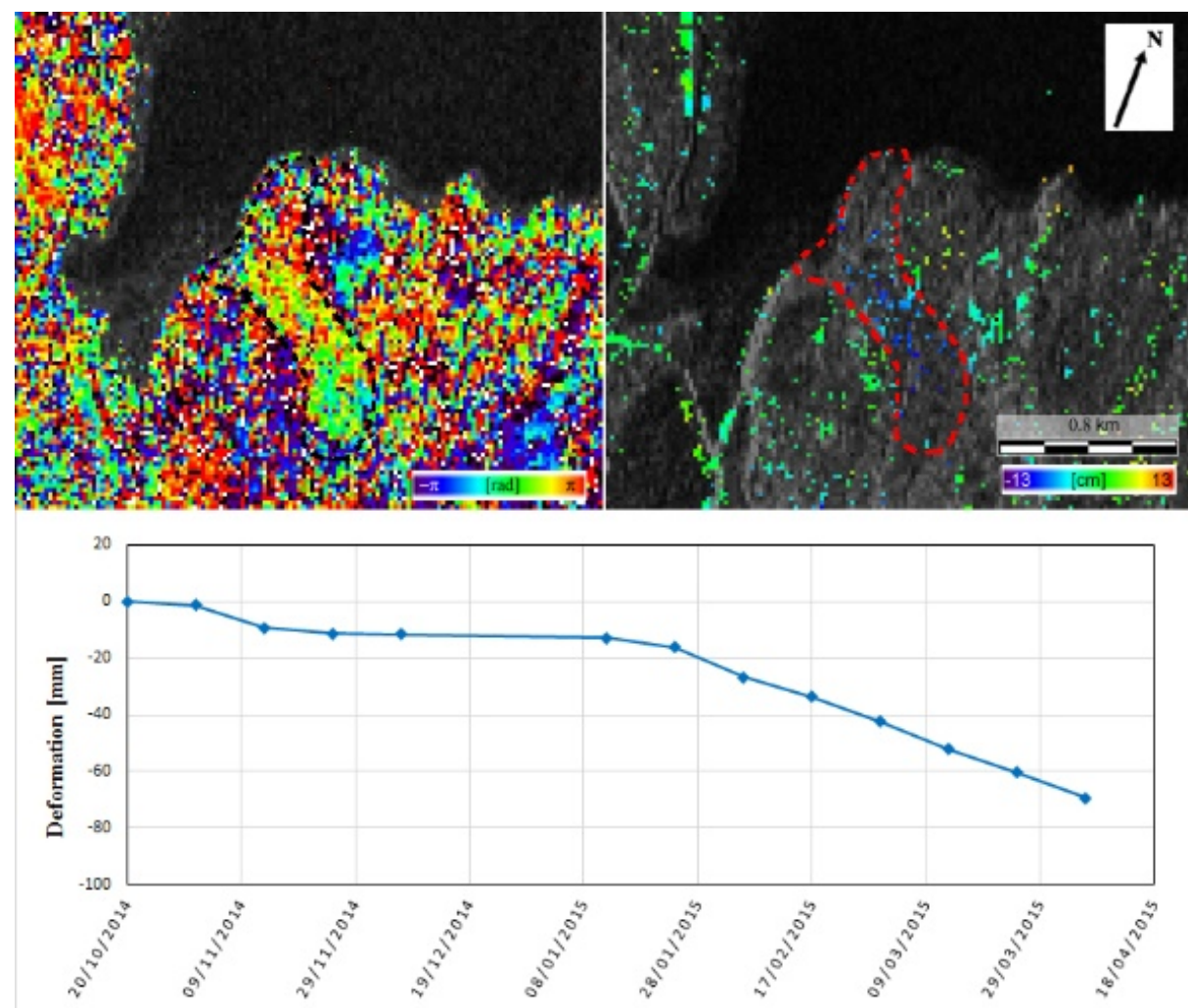

Figure 2: Example of landslide detection and monitoring using the simplified PSI approach. 12-day interferogram (upper left); accumulated deformation map (upper right); and average deformation time series (below).

discussed in detail in Devanthéry et al. (2014), are briefly described below.

- $\quad$ Given a stack of N complex SAR images, generate M redundant multi-look interferograms.

- $\quad$ Perform the so-called 2+1D phase unwrapping. This involves a spatial 2D phase unwrapping using the Minimum Cost Flow method (Costantini, 1998). A 1D phase unwrapping is then performed pixel wise over the $\mathrm{M}$ interferograms. This last step is able to detect and correct the errors generated during the 2D phase unwrapping stage, and provides tools to control the quality of the derived time series. It uses an iterative least squares procedure (Baarda, 1968; Björck, 1996; Förstner, 1986) which fully exploits the integer nature of the unwrapping errors; see for details Devanthéry el al. (2014).

- Estimation of the atmospheric component and its removal. This is performed by means of a set of spatio-temporal filters (Ferretti et al., 2000; 2001).

- Deformation velocity and residual topographic error (RTE) estimation. The deformation velocity and RTE are computed over a set of PSs, from the M wrapped atmosphere-free interferograms, using the method of the periodogram.

- $\quad$ RTE removal. The RTE phase component is removed from the wrapped APS-free interferograms. The linear deformation component can optionally be removed and then, in a later stage, added back to the deformation time series.

- Perform the final iteration of the $2+1 \mathrm{D}$ phase unwrapping. This involves a 2D phase unwrapping, followed by a $1 \mathrm{D}$ phase unwrapping. In this stage are generated the final deformation time series.

- Data geocoding.

\section{RESULTS}

In this section, we describe two deformation measurement results based on Sentinel-1 SAR data.

The first result was derived using the simplified PSI approach. It forms part of a project to detect and monitor landslides in the Molise region (Southern Italy). The analysis was based on 13 ascending images acquired in the period from October 2014 to April 2015. Figure 2 shows one of the landslides of the study area. The upper left image displays a 12-day interferogram. Even over such a short time period, a landslide deformation pattern can be detected in this interferogram. The approximate border of the landslide is highlighted by a black contour superposed to the colour-coded interferometric values. The upper right figure displays the accumulated deformation. In this case, the deformation pattern of the above landslide can be clearly distinguished from the surrounding areas. The observed displacement, shown in blue, is toward the satellite. The maximum line-of-sight displacements of the landslide are up to $13 \mathrm{~cm}$. The lower image illustrates a deformation time series of the landslide. In this case, the time series shows the average displacements of the entire landslide. One may notice that a period of quiescence occurs between the third and the sixth image, which is followed by an acceleration period. The maximum (average) deformation is approximately $70 \mathrm{~mm}$. Details of this analysis are provided in Barra et al. (2016). 

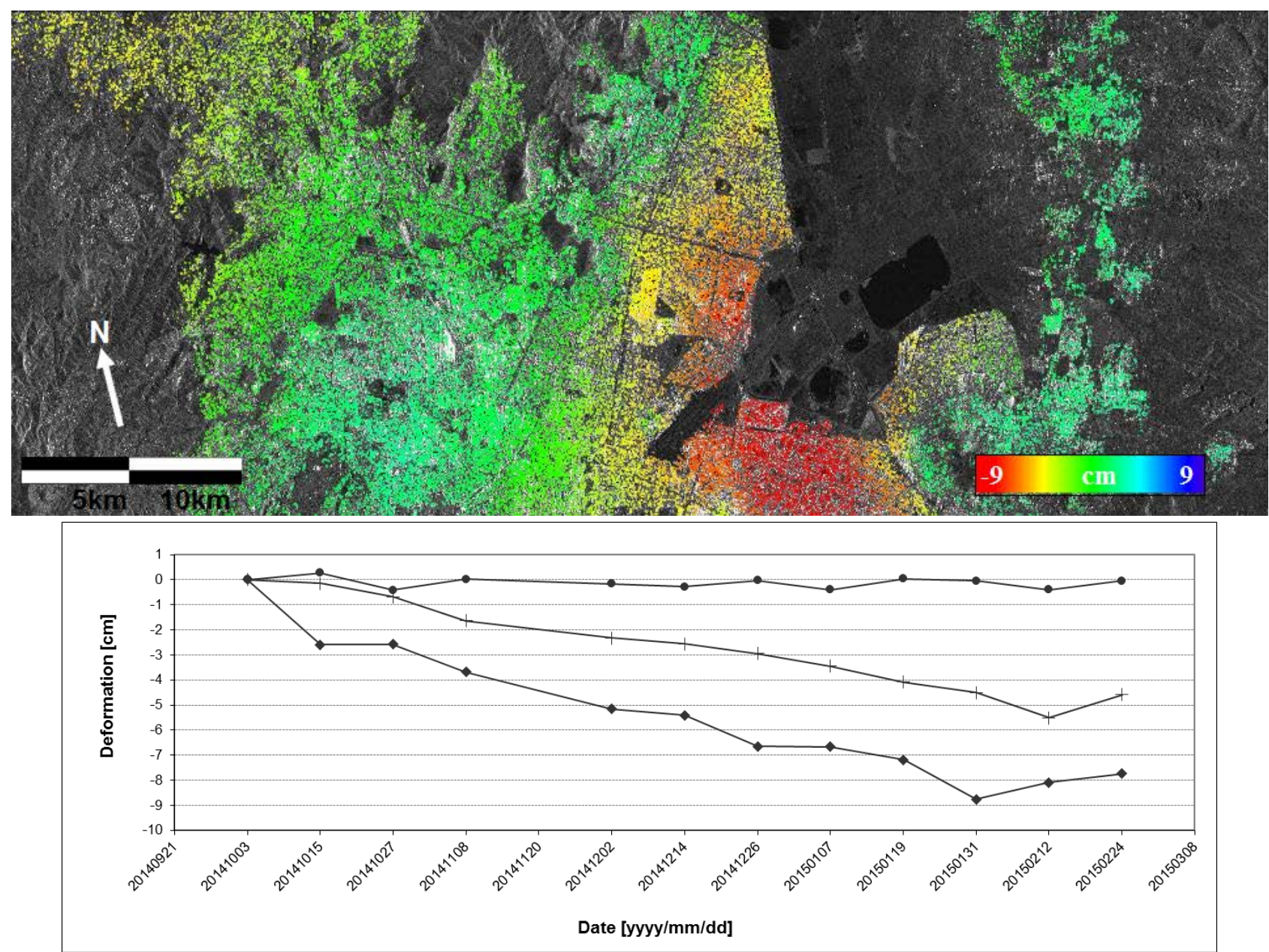

Figure 3: Example of a subsidence phenomenon measured using an advanced PSI approach. Accumulated deformation map (above); deformation time series over three points, one is located in the stable area and two in the deformation area (below).

The second result was derived using a full PSI approach. An IWS Sentinel-1 scene covers approximately 250 by $180 \mathrm{~km}$ and is composed of three swaths containing nine burst each. In this case, a single burst was processed, which encompasses a significant portion of Mexico DF. It covers an area of approximately 80 by $25 \mathrm{~km}$. Over the study area, a total of 720000 PSs were processed. The PS density over the urban area is $575 \mathrm{PS} / \mathrm{km}^{2}$.

The analysis was performed using 12 SAR IWS Sentinel-1 images and 66 (redundant) interferograms. The main PSI result, the accumulated deformation map, is shown in Figure 3. Green values correspond to stable areas, while negative values, in red, denote displacements away from the SAR sensor. All the values refer to the radar line-of-sight. The map shows a large area affected by subsidence (red colour), with accumulated displacement values up to $9 \mathrm{~cm}$ occurred during the four observed months. This is an example of very active subsidence phenomenon.

The time series of deformation represent one of the most interesting and advanced products derived with the PSI technique. They display the deformation history of each PS over the observed period. Three examples of deformation time series are shown in Figure 3. One of them displays a stable behaviour, while the others two indicate deformation values of up to 5 and $8 \mathrm{~cm}$, respectively.

\section{CONCLUSIONS}

In this paper two complementary approaches to process and analyze Sentinel-1 interferometric SAR data have been described. The first one is a simplified PSI approach that exploits the properties of the Sentinel-1 data: the high 12-day coherence and the reduced orbital tube. The second approach is a full PSI approach.

Two promising PSI results have been described. The first one concerns the detection and monitoring of landslides. In this application, the simplified PSI approach has demonstrated to be useful to take advantage of the coherence of consecutive 12-day interferograms. This will be further improved with the availability of the second Sentinel-1 satellite (Sentinel-1B), to be launched in 2016, which will allow us to obtain a 6-day revisiting cycle. The second example concerns an urban area. Using a full PSI approach a PS density of $575 \mathrm{PS} / \mathrm{km}^{2}$ has been achieved.

As mentioned above, the Sentinel- 1 results achieved so far are promising. The near feature efforts of the authors will be focused in adapting and improving the PSI data processing and analysis tools to process and monitor the deformation of wide area. The major challenge is to keep the quality of the measurements increasing, at the same time, the automation of the data analysis tasks. 


\section{ACKNOWLEDGEMENTS}

This work has been partially funded by the Spanish Ministry of Economy and Competitiveness through the project MIDES (Ref: CGL2013-43000-P).

\section{REFERENCES}

Baarda, W. (1968). A Testing Procedure for Use in Geodetic Networks; Kanaalweg 4, Rijkscommissie voor Geodesie: Delft, The Netherlands.

Barra, A., Monserrat, O., Mazzanti, P., Esposito, C., Crosetto, M., Scarascia Mugnozza, G. (2016). First insights on the potential of Sentinel-1 for landslides detection. Submitted to Geomatics Natural Hazards and Risks.

Bell, J.W., Amelung, F., Ferretti, A., Bianchi, M., Novali, F. (2008). Permanent scatterer InSAR reveals seasonal and longterm aquifer-system response to groundwater pumping and artificial recharge, Water Resour. Res., 44, W02407, doi:10.1029/2007WR006152.

Björck, A.. (1996). Numerical Methods for Least Square Problems. Siam: Philadelphia, PA, USA.

Bovenga, F., Wasowski, J., Nitti, D.O., Nutricato, R., Chiaradia, M.T. (2012). Using COSMO/SkyMed X-band and ENVISAT Cband SAR interferometry for landslides analysis, Remote Sens. Environ., 119, pp. 272-285.

Cigna, F., Osmanoglu, B., Cabral-Cano, E., Dixon, T.H., ÁvilaOlivera, J.A., Garduño-Monroy, V.H., DeMets, C., Wdowinski, S. (2012). Monitoring land subsidence and its induced geological hazard with Synthetic Aperture Radar Interferometry: A case study in Morelia, Mexico, Remote Sens. Environ., 117, pp. 146-161.

Colesanti, C., Ferretti, A., Prati, C., Rocca, F. (2003). Monitoring landslides and tectonic motions with the Permanent Scatterers Technique, Eng. Geol., 68, pp. 3-14.

Colesanti, C., Le Mouélic, S., Bennani, M., Raucoules, D., Carnec, C. Ferretti, A. (2005). Detection of mining related ground instabilities using the permanent scatterers technique - a case study in the east of France, Int. J. Remote Sens., 26(1), pp. 201-207.

Costantini, M. (1998). A novel phase unwrapping method based on network programming, IEEE Trans. Geosci. Remote Sens., 36, pp. 813-821.

Crosetto, M., Biescas, E., Duro, J., Closa, J., Arnaud, A. (2008). Generation of Advanced ERS and Envisat Interferometric SAR Products Using the Stable Point Network Technique, Photogrammetric Engineering and Remote Sensing, 74(4), pp. 443-450.

Crosetto, M., Monserrat, O., Iglesias, R., Crippa, B. (2010). Persistent Scatterer Interferometry: potential, limits and initial C- and X-band comparison". Photogrammetric Engineering and Remote Sensing, 76(9), pp. 1061-1069.

Crosetto, M., Monserrat, O., Cuevas-González, M., Devanthéry, N. (2016). Persistent Scatterer Interferometry: a review. ISPRS J. of Photogrammetry and Remote Sensing, 115, pp. 78-89.
Devanthéry, N., Crosetto, M., Monserrat, O., Cuevas-González, M., and Crippa, B. (2014). An approach to Persistent Scatterer Interferometry, Remote Sensing, 6(7), pp. 6662-6679.

Ferretti, A., Prati, C., Rocca, F. (2000). Nonlinear subsidence rate estimation using permanent scatterers in differential SAR interferometry. IEEE Trans. Geosci. Remote Sens., 47(5), pp. 2202-2212.

Ferretti, A., Prati, C., Rocca, F. (2001). Permanent scatterers in SAR interferometry, IEEE Trans. Geosci. Remote Sens., 39(1), pp. 8-20.

Förstner, W. (1986). Reliability, gross error detection and selfcalibration, ISPRS Commission III Tutorial on Statistical Concepts for Quality Control. ISPRS Int. Arch. Photogramm., 26, pp. 1-34.

Heleno, S.I.N., Oliveira, L.G.S., Henriques, M.J., Falcão, A.P., Lima, J.N.P., Cooksley, G., Ferretti, A., Fonseca, A.M., LoboFerreira, J.P., Fonseca, J.F.B.D. (2011). Persistent Scatterers Interferometry detects and measures ground subsidence in Lisbon, Remote Sens. Environ., 115, pp. 2152-2167.

Hilley, G. E., Bürgmann, R., Ferretti, A., Novali, F., Rocca, F. (2004). Dynamics of slow-moving landslides from Permanent Scatterer analysis, Science, 304(5679), pp. 1952-1955.

Jung, H., Kim, S., Jung, H., Min, K, Won, J. (2007). Satellite observation of coal mining subsidence by permanent scatterer analysis, Eng. Geol., 92, pp. 1-13.

Prats-Iraola, P., Scheiber, R., Marotti. L., Wollstadt, S., Reigber, A. (2012). TOPS interferometry with TerraSAR-X. IEEE Transactions on Geoscience and Remote Sensing, 50 (8), pp. 3179-3188.

Stramondo, S., Saroli, M., Tolomei, C., Moro, M., Doumaz, F., Pesci, A., Loddo, F., Baldi, P., Boschi, E. (2007). Surface movements in Bologna (Po Plain - Italy) detected by multitemporal DInSAR, Remote Sens. Environ., 110, pp. 304316.

Tomás, R., Márquez, Y., Lopez-Sanchez, J.M., Delgado, J., Blanco, P., Mallorquí, J.J., Martínez, M., Herrera, M., Mulas, J. (2005). Mapping ground subsidence induced by aquifer overexploitation using advanced Differential SAR interferometry: Vega Media of the Segura river (SE Spain) case study, Remote Sens. Environ, 98, pp. 269-283.

Vallone, P., Giammarinaro, M. S., Crosetto, M., Agudo, M., Biescas, E. (2008). Ground motion phenomena in Caltanissetta (Italy) investigated by InSAR and geological data integration, Eng. Geol., 98, pp. 144-155.

Yague-Martinez, N.; Prats-Iraola, P.; Rodriguez Gonzalez, F., Brcic, R., Shau, R., Geudtner, D., Eineder, M., Bamler, R. (2016). Interferometric Processing of Sentinel-1 TOPS Data. IEEE Transactions on Geoscience and Remote Sensing, 54(4), pp. 2220-2234. 